\title{
Pulmonary hypertension-specific therapy in patients with chronic respiratory insufficiency
}

\author{
To the Editor: \\ We read with much interest the article by HeLD et al. [1] regarding pulmonary hypertension ( $\mathrm{PH})$ due to \\ hypoventilation. In this retrospective study, the authors reported 18 patients with alveolar hypoventilation \\ (due to obesity or chronic obstructive pulmonary disease (COPD)) and daytime PH associated with \\ reduced exercise capacity. They showed that noninvasive positive-pressure ventilation (NIPPV) was \\ followed by significant improvement in haemodynamics and exercise capacity; thus, strongly supporting the \\ use of NIPPV in patients with hypoventilation and $\mathrm{PH}$, and suggesting a major role for hypoxia and \\ hypercapnia in $\mathrm{PH}[2]$.
}

As it is unknown whether PH-specific therapy targeting vasculopathy and remodelling of the pulmonary arteries may also have an impact in this setting, we retrospectively studied patients with chronic respiratory insufficiency and hypoventilation treated with long-term NIPPV who received off-label specific therapy for severe $\mathrm{PH}$.

We extracted from the French registry, in which all consecutive adult patients with $\mathrm{PH}$ are prospectively included with written consent [3], incident cases from our centre seen between 2006 and 2013 with the following criteria. 1) Chronic respiratory insufficiency with alveolar hypoventilation (daytime arterial carbon dioxide tension $>45 \mathrm{mmHg}$ and hypoxaemia before NIPPV), receiving long-term NIPPV for at least 6 months. 2) Precapillary PH: defined by mean pulmonary artery pressure (PAP) $\geqslant 25 \mathrm{mmHg}$ and pulmonary artery wedge pressure $\leqslant 15 \mathrm{mmHg}$ at right heart catheterisation. 3) Severe PH: defined by mean $\mathrm{PAP} \geqslant 35 \mathrm{mmHg}$ and/or cardiac index $<2 \mathrm{~L} \cdot \mathrm{min}^{-1} \cdot \mathrm{m}^{-2}$. 4) Off-label PH-specific therapy. 5) Available follow-up for at least 6 months. 6) Absence of associated conditions: chronic thromboembolic PH, postcapillary PH or severe left heart conditions. 18 out of 626 patients with precapillary PH were identified with chronic respiratory insufficiency, of whom 11 had severe $\mathrm{PH}$, including two treated with NIPPV for at least 6 months prior to initiation of $\mathrm{PH}$-specific therapy and followed for at least 6 months (table 1).

Both patients (one female and one male) had COPD with a forced expiratory volume in $1 \mathrm{~s}$ (FEV1)/forced vital capacity ratio of $49 \%$ and $43 \%$, respectively, FEV1 of $45 \%$ predicted and $36 \%$ pred, respectively, and a diffusing capacity of the lung for carbon monoxide of $27 \%$ pred and $41 \%$ pred, respectively. Body mass index was $24 \mathrm{~kg} \cdot \mathrm{m}^{-2}$ and $35 \mathrm{~kg} \cdot \mathrm{m}^{-2}$, respectively. Neither patient had associated sleep apnoea syndrome or obesity hypoventilation syndrome. Both patients were efficiently treated with NIPPV (with an inspiratory pressure of $15 \mathrm{mmHg}$ and $20 \mathrm{mmHg}$, respectively) and $1.5 \mathrm{~L} \cdot \mathrm{min}^{-1}$ supplemental oxygen overnight for 6 months before $\mathrm{PH}$ was diagnosed, with adequate correction of night-time and daytime hypoxaemia and hypercapnia ( $44 \mathrm{mmHg}$ and $45 \mathrm{mmHg}$, respectively). The patients received a further $5 \mathrm{~L} \cdot \mathrm{min}^{-1}$ and $3 \mathrm{~L} \cdot \mathrm{min}^{-1}$, respectively, of oxygen continuously during the daytime. Routine echocardiography suggested presence of $\mathrm{PH}$ in both patients, and right heart catheterisation demonstrated severe precapillary $\mathrm{PH}$ with preserved cardiac index. After discussion, it was considered that severe $\mathrm{PH}$ may contribute to their functional limitation. Patients' consent was obtained and off-label sildenafil therapy was initiated, with later combination with bosentan in one case and diuretics in both cases. In patient 1, no clinical or haemodynamic improvement was observed. Patient 2 had no clinical or functional improvement, despite long-term haemodynamic improvement with increase in cardiac index and decrease in mean PAP. Inhaled bronchodilators, NIPPV and supplemental oxygen were unchanged. No significant change was observed in arterial oxygen tension, or oxygen saturation at rest or during 6-min walking test over more than 1 year of follow-up. However, hypoxaemia worsened in patient 1 after 38 months of sildenafil treatment, with an increase in alveolar-arterial partial pressure of oxygen gradient, which partially corrected after sildenafil had been discontinued.

These observations of COPD hypoventilation with severe PH differ from the study of HeLD et al. [1], which predominantly included patients with obesity hypoventilation syndrome. This report emphasises that severe precapillary $\mathrm{PH}$ is rare in the setting of chronic respiratory insufficiency, even in a large Dept of Respiratory Medicine and referral centre for $\mathrm{PH}$, further suggesting that $\mathrm{PH}$-specific drug therapy is unlikely to be 


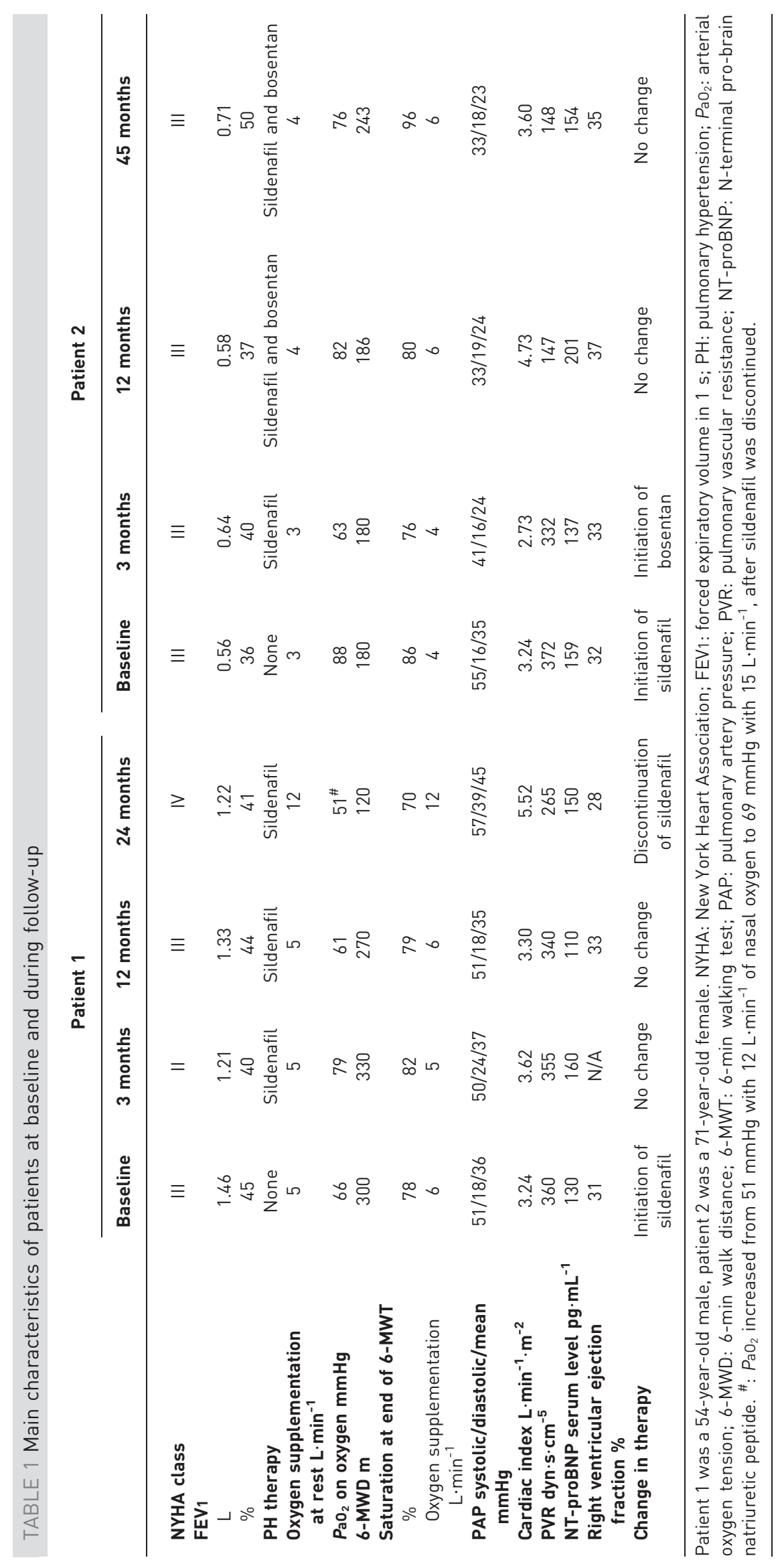


beneficial in this setting. As stated at a recent international conference on $\mathrm{PH}, \mathrm{PH}$-specific drugs are not recommended in patients with $\mathrm{PH}$ associated with chronic respiratory diseases (group 3), and treatment should focus on managing the underlying disease [4]. Oxygen supplementation may stabilise $\mathrm{PH}$ in patients with COPD [5], and NIPPV may improve haemodynamics in patients with alveolar hypoventilation [1]. Although off-label treatment is sometimes considered in individuals with severe $\mathrm{PH}$ when functional limitation is considered to be related to pulmonary vascular disease, there is currently little if any evidence that $\mathrm{PH}$ therapy may be beneficial in this setting, with further anecdotal evidence that treatment may increase hypoxaemia through ventilation/perfusion mismatch.

We therefore strongly agree with HeLD et al. [1] that correction of hypoventilation should be the main objective of management in chronic respiratory insufficiency, even in the presence of severe PH.

@ERSpublications

Correction of hypoventilation should be the main objective in chronic respiratory insufficiency, even with severe PH http://ow.ly/wxvcN

Vincent Cottin ${ }^{1,2}$, Marjorie Lorillou ${ }^{3}$, Chahéra Khouatra ${ }^{1,2}$, Julie Traclet ${ }^{3}$, Pascale Nesme ${ }^{3}$ and Jean-François Cordier ${ }^{1,2}$ ${ }^{1}$ Hospices Civils de Lyon, Louis Pradel hospital, Service de pneumologie - Centre de référence national des maladies pulmonaires rares, Centre de compétence de l'hypertension pulmonaire sévère, Lyon, France. ${ }^{2}$ Université de Lyon, Université Claude Bernard Lyon 1, INRA, UMR754 INRA-Vetagrosup EPHE IFR 128, Lyon, France. ${ }^{3}$ Hospices Civils de Lyon, Croix-Rousse hospital, Dept of Respiratory Diseases, Lyon, France.

Correspondence: Vincent Cottin, Hôpital Louis Pradel, Claude Bernard Lyon 1 University, 28 Avenue du Doyen Lepine, 69677 Lyon, France. E-mail: vincent.cottin@chu-lyon.fr

Received: March 212014 | Accepted after revision: April 162014

Conflict of interest: Disclosures can be found alongside the online version of this article at erj.ersjournals.com

\section{References}

$1 \quad$ Held M, Walthelm J, Baron S, et al. Functional impact of pulmonary hypertension due to hypoventilation and changes under noninvasive ventilation. Eur Respir J 2014; 43: 156-165.

Naeije R. Pulmonary hypertension in hypoventilation syndromes. Eur Respir J 2014; 43: 12-15.

3 Humbert M, Sitbon O, Chaouat A, et al. Pulmonary arterial hypertension in France: results from a national registry. Am J Respir Crit Care Med 2006; 173: 1023-1030.

4 Seeger W, Adir Y, Barbera JA, et al. Pulmonary hypertension in chronic lung diseases. J Am Coll Cardiol 2013; 62: D109-D116.

5 Zielinski J, Tobiasz M, Hawrylkiewicz I, et al. Effects of long-term oxygen therapy on pulmonary hemodynamics in COPD patients: a 6-year prospective study. Chest 1998; 113: 65-70.

Eur Respir J 2014; 44: 819-821 | DOI: 10.1183/09031936.00054214 | Copyright @ERS 2014

\section{From the author:}

I would like to thank V. Cottin and co-workers for their interest in our recently published study [1]. Their comments emphasise our conclusion that the treatment of the underlying disease should be the favoured strategy.

Since both patients did not have a reduced cardiac index, when treatment with sildenafil and bosentan was started the lack of a significant improvement was not really surprising. The two patients reported by V. Cottin and co-workers showed different reactions. Patient one deteriorated dramatically in World Health Organization (WHO) functional class and 6-min walk distance (6MWD) "despite" (or due to!) a decrease of pulmonary vascular resistance. This patient showed an excessive increase of cardiac index and a worsening of oxygenation, probably the consequence of increasing shunt perfusion resulting from reversing of vasoconstriction.

Patient two showed an early decrease of pulmonary artery pressure, no change in WHO functional class, and stable oxygenation and cardiac index, but a late improvement in 6MWD. It is questionable whether a short-term follow-up period is appropriate for patients with pulmonary hypertension due to obstructive lung disease. Patients with pulmonary hypertension and chronic obstructive pulmonary disease showed a maximum improvement of $6 \mathrm{MWD}$ after 8-9 months, thus, it is probable that these patients need a longer period in order to improve their functional capacity rather than decrease their pulmonary artery pressure [2].

As MeYer et al. [3] reported on respiratory muscle dysfunction and respiratory insufficiency in patients with idiopathic pulmonary arterial hypertension, in our daily practice we have to differentiate whether a patient presenting with severe pulmonary hypertension and hypoventilation is a patient with pulmonary 